\title{
Article \\ Effect of Polyethylene Glycol Treatment on Acetic Acid Emissions from Wood
}

\author{
Sarah Hunt ${ }^{1, *}$, Josep Grau-Bove ${ }^{2}$, Eleanor Schofield ${ }^{3, *}$ and Simon Gaisford ${ }^{1} \mathbb{D}$ \\ 1 UCL School of Pharmacy, University College London, London WC1N 1AX, UK; s.gaisford@ucl.ac.uk \\ 2 Institute for Sustainable Heritage, University College London, London WC1H 0NN, UK; \\ josep.grau.bove@ucl.ac.uk \\ 3 Mary Rose Trust, Portsmouth PO1 3GW, UK \\ * Correspondence: sarah.hunt.15@ucl.ac.uk (S.H.); E.Schofield@maryrose.org (E.S.)
}

check for updates

Citation: Hunt, S.; Grau-Bove, J.; Schofield, E.; Gaisford, S. Effect of Polyethylene Glycol Treatment on Acetic Acid Emissions from Wood. Forests 2021, 12, 1629. https:// doi.org/10.3390/f12121629

Academic Editors: Magdalena Broda and Callum A. S. Hill

Received: 20 October 2021

Accepted: 22 November 2021

Published: 25 November 2021

Publisher's Note: MDPI stays neutral with regard to jurisdictional claims in published maps and institutional affiliations.

Copyright: (c) 2021 by the authors. Licensee MDPI, Basel, Switzerland. This article is an open access article distributed under the terms and conditions of the Creative Commons Attribution (CC BY) license (https:// creativecommons.org/licenses/by/ $4.0 /)$.

\begin{abstract}
Acetic acid is known to be emitted from sound wood and can accelerate damage to heritage materials, particularly metals. However, few studies have investigated the extent of acetic acid emissions from archaeological wood. This research utilised Solid-Phase-Micro-Extraction (SPME) GC-MS and lead coupon corrosion to identify volatile emissions from polyethylene glycol (PEG)-treated archaeological wood from the Mary Rose collection and assess if they could cause accelerated damage. In addition, the effect of PEG treatment on acetic acid emissions was investigated using sound wood samples. For sound wood, the PEG treatment acted as a barrier to acetic acid emissions, with higher-molecular-weight PEGs preventing more emissions. Archaeological wood, despite its age and high-molecular-weight PEG treatment, still emitted detectable concentrations of acetic acid. Moreover, they emitted a wider array of compounds compared to sound wood, including carbon disulphide. Like sound wood, when the archaeological wood samples were in a sealed environment with lead coupons, they caused accelerated corrosion to lead. This evidences that archaeological wood can emit high enough concentrations of volatile compounds to cause damage and further investigation should be performed to evaluate if this can occur inside museum display cases.
\end{abstract}

Keywords: waterlogged wood; PEG treatment; acetic acid; volatile emissions; GC-MS

\section{Introduction}

Sound wood emits acetic acid, which is known to accelerate damage to a range of heritage materials [1-3]. Hence, it is accepted that uncoated wood should not be used in the construction or decoration of museum display cases, as, due to their low air exchange rate, unacceptable concentrations of damaging volatile emissions can be observed [4]. Moreover, modern design display cases favour a low air exchange rate as this allows better humidity control. However, because of this, volatile compounds emitted from within the display case will dissipate slower, and therefore other sources of potential emissions inside display cases should be investigated.

In contrast to sound wood, much less research has been performed on acetic acid emissions from wooden artefacts [5]. In addition, these are often more complex materials than sound wood due to degradation and the requirement of a consolidant. Polyethylene glycol (PEG), which is often used to consolidate archaeological organic objects, is known to affect molecular permeation transport properties of materials [6]. Therefore, it is likely that the application of PEG into and onto wood will affect the emission rate of volatile compounds. Additionally, PEG can also emit volatile compounds-previous work identified formic acid as a marker for PEG degradation but found limited formic acid in PEG-treated archaeological wood samples from the Vasa, the Skuldelev Viking ships and the Bremen Cog, concluding that the extent of PEG degradation was thought to be minimal approximately 45 years after it was applied [7]. However, whilst the concentration emitted might be minimal with respect to PEG degradation, the volatile formic acid emitted could 
have a negative impact on other heritage materials if allowed to concentrate inside display cases over time. Additionally, it could lower the $\mathrm{pH}$ of the wood and hence accelerate hydrolysis of wood cellulose fibre [8].

This paper uses SPME-GC-MS to identify the emissions from PEG-treated archaeological wood from the Mary Rose collection-a collection which contains the wooden hull and contents of the Mary Rose, an English Tudor warship. These emissions included acetic acid and carbon disulphide, which are known to damage some heritage materials. To investigate this, lead coupon corrosion experiments were also used to evaluate if the volatile emissions accelerated damage to lead. Lead was chosen due to its sensitivity towards acetic acid [2]. Additionally, the effect of PEG treatment on acetic acid emissions from sound wood was investigated, which was found to reduce acetic acid emissions.

\section{Materials and Methods}

\subsection{Samples}

To imitate standard conservation treatments on archaeological wood, modern cubes of oak (Quercus robur L.) wood, $1.5 \mathrm{~cm}^{3}$, were soaked in 40\% solutions of either 200-, 400or 600-molecular-weight PEG for approximately three years. Prior to analysis, they were dried at room temperature. Additionally, cubes of untreated wood and PEG 600-treated wood were soaked in $50 \mathrm{~mL}$ of distilled water for four days and then air dried at room temperature prior to analysis in order to evaluate the effects of washing on the acetic acid emissions.

Four PEG-treated archaeological artefacts were obtained from the Mary Rose collection-a collection of 16th-century objects from Henry VIII's flagship, including the hull of the ship which was excavated in 1982-and PEG treatment started in 2004. The age of the PEG treatment of the other artefacts varies, with some conserved as soon as they were raised in the 1970s and 1980s. Three of these (Artefact 1-3) were PEG treated at the same time as each other, using the same method-soaking in 10\% PEG 600, 20\% PEG 600, 30\% PEG 4000, followed by freeze drying and surface treatment with PEG 4000 where required. The only exception is Artefact 4, which was sprayed with 40\% PEG 200, then 65\% PEG 2000 followed by controlled air drying. The treatment of the woods used in this study is summarised in Table 1. The approximate surface areas of Artefact 1, 2, 3 and 4 were $0.10,0.08,0.05$ and $0.05 \mathrm{~m}^{2}$, respectively.

\subsection{SPME GC-MS Analysis}

Treated and untreated sound wood samples (sound wood 1-4) were sealed for nine days in $20 \mathrm{~mL}$ headspace sample vials (Thermo Scientific Chromacol, Waltham, MA, USA) with screw caps and silicone/PTFE liners. For sterilisation, all sample vials, caps and seals were heated in an oven at $150{ }^{\circ} \mathrm{C}$ for at least $24 \mathrm{~h}$ prior to use.

The PEG-treated archaeological artefacts (Artefacts 1-4) were placed inside 5 L Tedlar sample bags with a single polypropylene fitting (SKC, Blandford Forum, UK). The sample bag was then resealed using a packer poly heat sealer. A vacuum pump was used to evacuate the air, which was then replaced with nitrogen (minimum 99.998\% purity). The artefacts were sealed for nine days.

The SPME-GC-MS method used in this study was developed by Curran et al. [9]. A Divinylbenzene/Carboxen/Polydimethylsiloxane SPME fibre was exposed to the headspace of the vials and Tedlar bags for one hour at room temperature. It was then heated in the injection port of a gas chromatograph (Perkin Elmer Clarus 500, Beaconsfield, UK) at $250{ }^{\circ} \mathrm{C}$ in splitless mode for one minute. A $60 \mathrm{~m}$ in length and $0.25 \mathrm{~mm}$ in diameter column (VOCOL Sigma-Aldrich, St. Louis, MO, USA) was used. The GC was coupled to a Perkin Elmer Clarus 560D mass spectrometer. Mass spectra were collected under electron ionisation mode at $70 \mathrm{eV}$ and recorded from $\mathrm{m} / \mathrm{z} 45$ to 300 .

The separation method was such that acetic acid eluted between 11.3 and $11.7 \mathrm{~min}$. The extracted-ion chromatogram obtained from the intensity of the signal at a mass to charge ratio of 60 was used to estimate the acetic acid peak intensity. To account for 
instrument day-to-day variation, the acetic acid peak was divided by that of the doublet peak in the MISA Group 17 Non-Halogen Organic Mix standard (Supelco, Bellefonte, PA, USA) which eluted at $21 \mathrm{~min}$.

Table 1. Summary of samples used in this study. Artefacts 1 to 4 are pre-treated wood from the Mary Rose collection. The collection reference number is indicated between brackets when available. The samples "sound wood" 1 to 4 have been treated during this research.

\begin{tabular}{|c|c|c|}
\hline Sample & Species & Treatment \\
\hline $\begin{array}{l}\text { Artefact } 1 \\
(83 \mathrm{~A} 0637)\end{array}$ & Oak (Quercus robur) & $\begin{array}{l}\text { 10\% PEG 600, 20\% PEG 600, } \\
30 \% \text { PEG 4000, freeze dried, } \\
\text { surface PEG } 4000 \text { treatment }\end{array}$ \\
\hline Artefact 2 (90A0049) & Ash (Fraxinus excelsior L.) & $\begin{array}{l}10 \% \text { PEG 600, 20\% PEG 600, } \\
30 \% \text { PEG 4000, freeze dried, } \\
\text { surface PEG } 4000 \text { treatment }\end{array}$ \\
\hline Artefact 3 (87A0068) & $\begin{array}{l}\text { Elm (Ulmus procera Salisb.) or } \\
\text { Beech (Fagus sylvatica L.) }\end{array}$ & $\begin{array}{l}10 \% \text { PEG 600, 20\% PEG 600, } \\
30 \% \text { PEG 4000, freeze dried, } \\
\text { surface PEG } 4000 \text { treatment }\end{array}$ \\
\hline Artefact 4 & Oak (Quercus robur) & $\begin{array}{l}\text { Sprayed with } 40 \% \text { PEG 200, then } 65 \% \\
\text { PEG 2000, air dried. }\end{array}$ \\
\hline Sound wood 1 & Oak (Quercus robur) & No treatment \\
\hline Sound wood $1 \mathrm{~W}$ & Oak (Quercus robur) & Sound wood 1 , washed and air dried \\
\hline Sound wood 2 & Oak (Quercus robur) & $40 \%$ PEG 200, air dried \\
\hline Sound wood 3 & Oak (Quercus robur) & $40 \%$ PEG 400 , air dried \\
\hline Sound wood 4 & Oak (Quercus robur) & 40\% PEG 600, air dried \\
\hline Sound wood $4 \mathrm{~W}$ & Oak (Quercus robur) & Sound wood 4, washed and air dried \\
\hline
\end{tabular}

Analysis of empty vials and Tedlar bags was performed. No acetic acid was detected from the sealed Tedlar bags, including one which was sealed for 17 weeks. However, a small acetic acid peak was detected from the blank headspace vials. Nine measurements of the empty vials were used to estimate the limit of detection (LOD) for acetic acid measurements from Chromacol headspace vials.

\subsection{Lead Coupon Exposure}

Lead foil, approximate thickness $0.25 \mathrm{~mm}$ and $>99.96 \%$ purity, purchased from Merck Millipore, was mechanically prepared by grinding with a glass bristle brush. It was then cut into strips, approximately 10 by $20 \mathrm{~mm}$ and degreased in acetone. The lead strips were exposed in custom holders, made from a clear polymethyl methacrylate. An electronic microbalance (4401 MP8, Sartorius, Goettingen, Germany) with a sensitivity of $10 \mu \mathrm{g}$ was used to weigh the metal strips before and after exposure. All weight measurements were performed in triplicate. The initial mass was used to calculate the surface area and the mass change per lead surface area calculated.

The sound wood samples (sound wood 1-4) were sealed in $70 \mathrm{~mL}$ screw top amber vials with polyethylene lids for 15 weeks. Additionally, a vial containing $5 \mathrm{~mL}$ of saturated sodium bromide solution was used as a control for the sound wood. Two lead coupons were placed in each vial. The average conditions outside the vials were $25^{\circ} \mathrm{C}$ and $37 \% \mathrm{RH}$, which was recorded using an EasyLog USB logger (LASCAR electronics, Salisbury, UK). The artefacts (Artefacts 1-4) were sealed inside 5 L Tedlar bags with three lead coupons for 17 weeks. Additionally, coupons were placed in an empty $5 \mathrm{~L}$ Tedlar bag as a control for the artefacts. The average temperature and $\mathrm{RH}$ outside the Tedlar bags were $21^{\circ} \mathrm{C}$ and $36 \%$, which was recorded using an EasyLog USB logger (LASCAR electronics, Salisbury, UK). 


\section{Results and Discussion}

HS-SPME-GC-MS analysis of sound wood 1 identified volatile acetic acid, toluene, hexanal, furfural, alpha-pinene, octantal, nonanal and decanal in the HS above the sample, with acetic acid being the dominant peak as shown in Figure 1. The two intense peaks in Figure 1 are siloxanes and are not thought to be from the sample, but rather contamination from the SPME fibre, injection port, or column. The literature also reports similar emission profiles from oak, with high acetic acid emissions, which is due to the hydrolysis of acetyl groups in hemicellulose [10]. Furan derivative compounds, such as furfural, are cellulose degradation products and hence could be used as an indicator of cellulose degradation [11], whereas the aldehydes detected are thought to be formed by oxidation of unsaturated fatty acids within the wood [10].

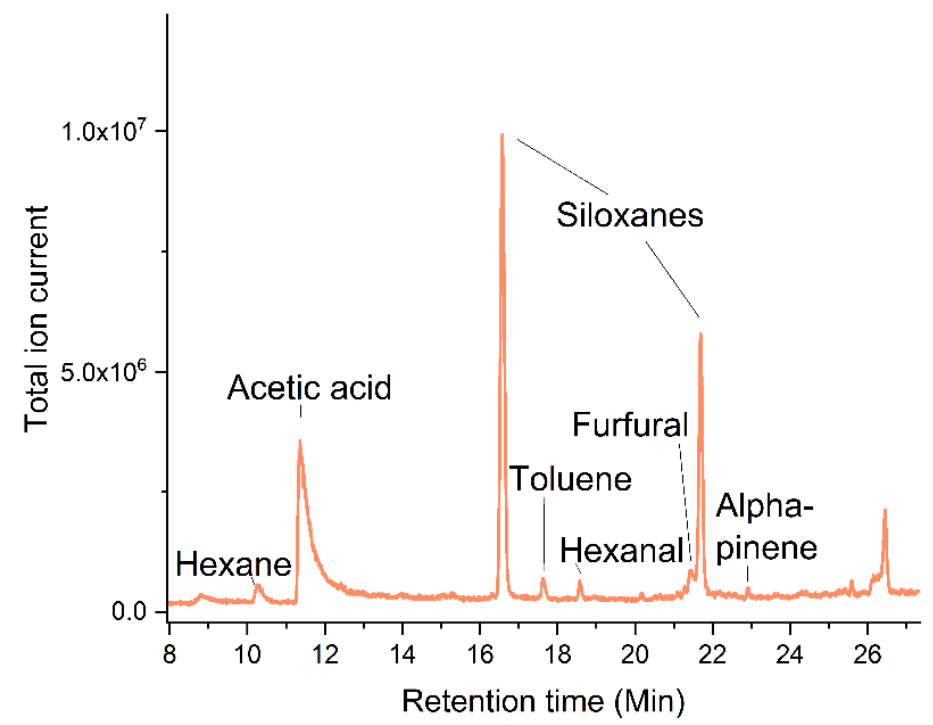

Figure 1. HS-SPME-GC-MS chromatogram of untreated sound wood (sound wood 1). The siloxanes peaks are highly unlikely to be from the sample, but rather a contaminant from the SPME fibre, GC-MS inlet and/or column.

Terpene compounds, such as alpha pinene, are present in woods as natural oils [12]. No formic acid was detected from the untreated wood as the lowest detectable mass to charge ratio in this study was 45 , whereas the main ion in the mass spectrum of formic acid is 29. Additionally, the SPME fibre used has a poor affinity for small polar molecules, such as formic acid. Therefore, this analysis cannot provide information on formic acid emissions as the sensitivity for this compound is likely to be low. Whilst oak is expected to emit formic acid, the concentration emitted has been reported to be around thirty times smaller compared to acetic acid [1]. Therefore, a different method would have to be used to detect low concentrations of formic acid-SPME fibres have been previously used to detect formic acid in air samples. However, to achieve this, a polyacrylate-coated fibre was used which is more suitable for polar compounds.

In comparison to the untreated wood, the PEG-treated wood samples (sound wood 2, 3 and 4), had lower emissions, particularly after treatment with PEG 400 and 600 molecular weight, with only alphapinene and toluene being consistently detected. No other intense peaks were detected from the PEG-treated samples, and hence the PEG is not believed to be significantly off-gassing compared to the wood. Therefore, there was no evidence to suggest that the recent PEG treatment increased the variety or concentration of emissions from sound wood. Rather, the recently applied PEG treatment appears to reduce emissions dramatically. Therefore, as the PEG was only recently applied to the sound wood samples used in this study, and they are unlikely to contain iron compounds, which are postulated to accelerate PEG degradation in archaeological wood, minimal PEG degradation products are expected in the samples [13]. 


\subsection{Acetic Acid Emissions and Effect of Washing}

The concentration of volatile acetic acid in the vial for the PEG-treated samples (sound wood 2-4) is reduced compared to the untreated sample (sound wood 1). The samples treated with 400- and 600-molecular-weight PEG have acetic acid peak areas below the limit of detection. This reduction could be explained by the presence of PEG or by other steps in the conservation treatment, such as the washing of the samples. To explore further this possibility, volatile emissions from washed samples were measured. As shown in Figure 2, acetic acid emissions from the washed untreated sample (sound wood $1 \mathrm{~W}$ ) were approximately $80 \%$ lower compared to the unwashed sample (sound wood 1 ). This is due to free acetic acid being removed by aqueous washing, which is a major source of volatile acetic acid from wood. This is further supported by $\mathrm{pH}$ measurements of the washings, which were $\mathrm{pH} 3.5$. Moreover, all detected volatile compounds also decreased after washing.

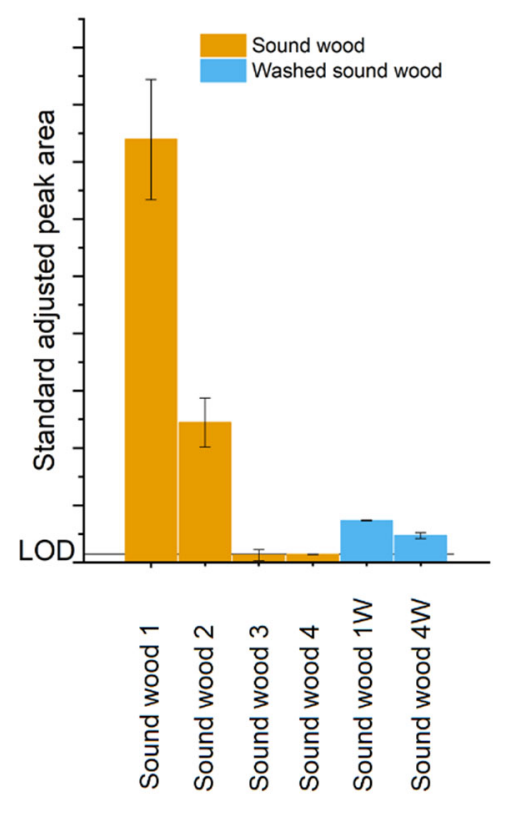

(a)
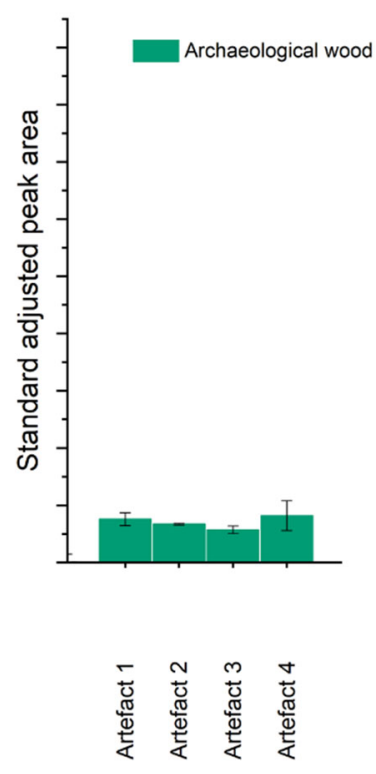

(b)

Figure 2. Acetic acid peak areas detected by SPME GC-MS analysis for sound wood and washed sound wood (a) and archaeological wood (b).

Conversely, after washing the PEG 600-treated sample (sound wood $4 \mathrm{~W}$ ), the acetic acid emissions increased. We hypothesise that, as aqueous washing partially removes the PEG treatment, the PEG is acting as an impenetrable barrier for acetic acid emissions. Hence, when this barrier is removed, emissions increase. Whilst 600-molecular-weight PEG will penetrate into archaeological wood, very little PEG can be accommodated within sound wood [14]. Therefore, it could reside predominantly on the surface of the wood and act as an efficient barrier to volatile compounds. In contrast, PEG 200 will penetrate more easily deeper into the core of the wood, due to its smaller size, and hence may not form as efficient a barrier on the wood surface [14]. Additionally, lower-molecular-weight PEGs have lower viscosities which will aid transportation from solution to the bulk of the sample.

Whilst washing dramatically decreases acetic acid emissions from treated sound wood, it is thought that over time, due to the hydrolysis of the acetyl groups in the wood, the free acetic acid content will increase, and hence acetic acid emissions will increase again [1]. Whilst this factor could partially explain why PEG-treated sound wood has lower acetic acid emissions, due to the wood being recently soaked in aqueous PEG solutions during treatment, it cannot explain why additional washing of PEG-treated wood increases acetic 
acid emissions. It is therefore believed increased acetic acid emissions are the result of PEG removal during washing.

\subsection{Emissions from Archaeological Wood}

In comparison to sound wood, emissions from the archaeological samples were much more complex-a wider array of compounds was detected as shown in Figure 3. Despite the increased complexity of the emissions, there was good agreement between the four artefacts, with similar compounds being detected but with varying intensity, as shown in Figure $3 \mathrm{~b}$. Similar to the sound wood, no glycol compounds were detected, and hence it is again concluded that it is the wood, rather than the PEG treatment that is contributing to the volatile emissions the archaeological woods. The PEG treatment does not appear to almost eliminate emissions as it did for sound oak. However, no untreated archaeological wood was available to be tested, it is not known what effect the PEG treatment has on emissions.

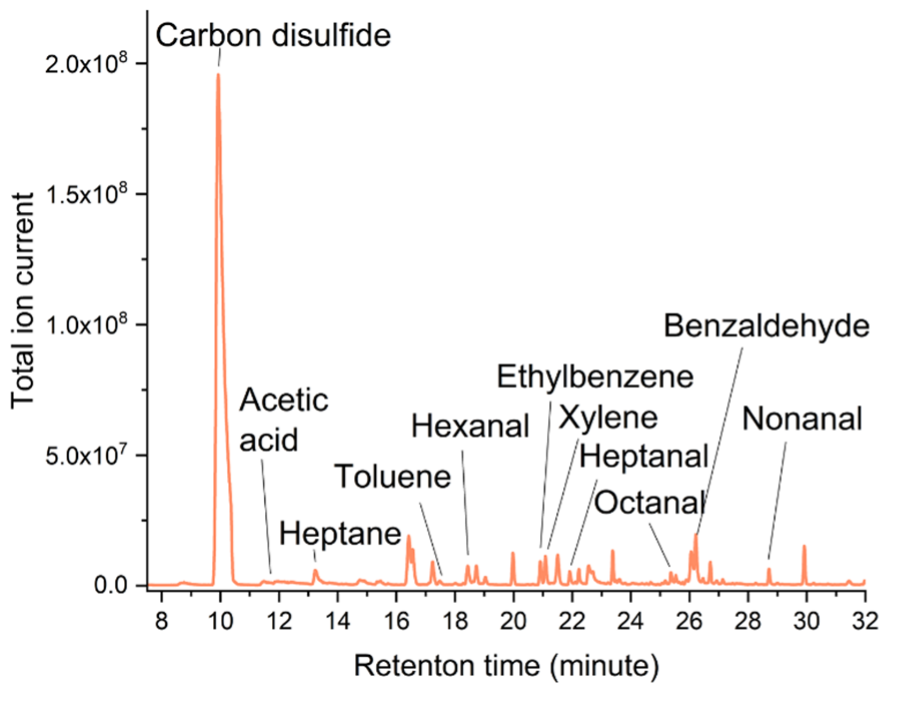

(a)

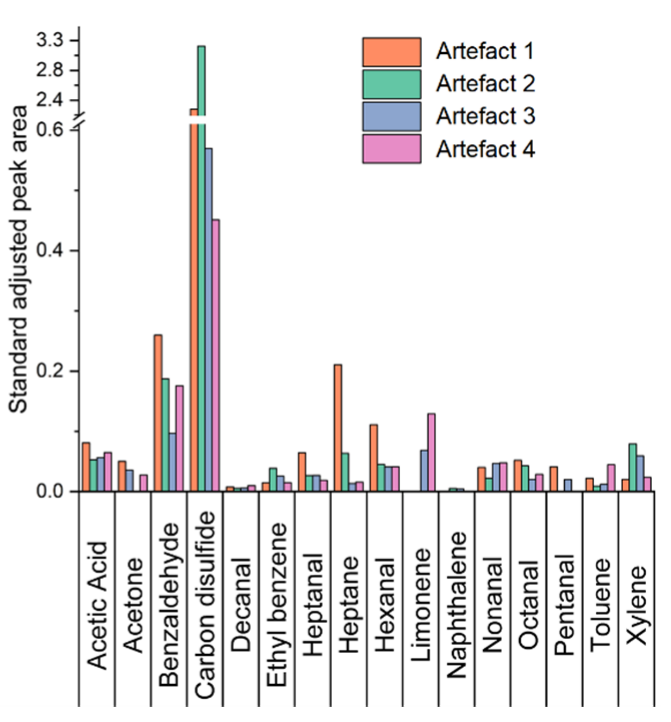

(b)

Figure 3. Compounds detected by HS-SPME-GC-MS analysis from Mary Rose wooden artefacts after 48 days inside a Tedlar bag. Right, (a) Chromatogram of Artefact 1 (87A0068). Left, (b) standard adjusted peak areas of Artefacts 1 to 4.

All the PEG-treated archaeological artefacts had similar acetic acid peak areas. It should be noted that the acetic acid peak areas for sound and archaeological wood cannot be directly compared due to the different sample setup. As archaeological wood is likely to have a significantly reduced free acetic acid content compared to sound wood, further washing is unlikely to significantly decrease its acetic acid emissions significantly. However, the barrier properties of PEG could influence emissions-high-molecular-weight PEGs are commonly applied as surface treatments and could therefore also act as barriers for volatile emissions from the wood. Whilst this study could not compare acetic acid emissions from PEG-treated and untreated archaeological wood, due to the difficulty in obtaining the latter, it was found that PEG-treated archaeological artefacts did emit acetic acid, and therefore, unlike sound wood, the PEG treatment does not completely prevent emissions.

In addition to a reduced acetic acid peak area and a greater number of aromatic and carbonyl compounds detected, the most significant difference compared to sound oak is the presence of an intense peak attributed to carbon disulphide. The Mary Rose wood, as well as other shipwreck timbers, are known to contain hydrogen sulphide, which is produced by bacteria [15]. This compound can react with lignin to form thiols, which further oxidise to sulphate esters and sulphonates. However, disulphides, such as carbon disulphide, have been identified as intermediate compounds [16,17]. 


\subsection{Corrosion Caused to Lead by Sound and Archaeological Wood}

Emissions from sound and archaeological wood were found to accelerate lead corrosion compared to the control environment, as shown in Figure 4. The lead coupon results for sound and archaeological wood are not directly comparable due to differences in other parameters, such as size and shape of the object, temperature and humidity. However, these results highlight that, despite the wood's age and likely reduced acetyl content, archaeological wood can cause a similar magnitude of damage to lead as sound wood.

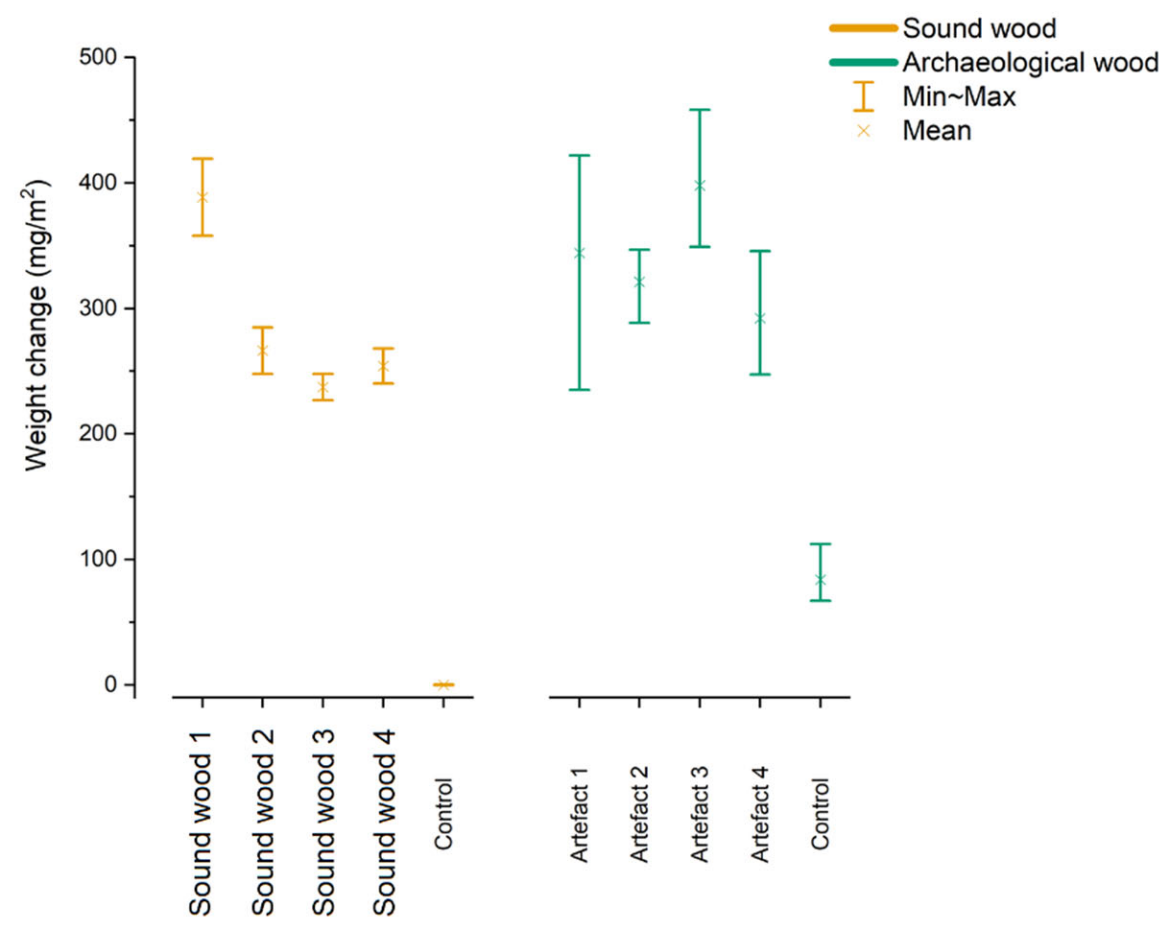

Figure 4. Lead coupon weight change after exposure to sound wood 1-4 in sealed vials for 15 weeks, and archaeological wood (Artefacts 1-4) sealed inside Tedlar bags for 17 weeks.

Raman spectra of the lead coupons exposed to sound wood 1 and 2 had the same peaks as spectra of lead coupons after exposure to acetic acid. In contrast, no detectable peaks were observed for the sound woods treated with higher-molecular-weight PEGs (sound wood 3 and 4). This is further evidence that higher-molecular-weight PEG treatment reduces acetic acid emissions compared to untreated wood and wood treated with PEG 200.

\section{Conclusions}

The treatment of sound wood with PEG was found to reduce the amount of volatile acetic acid emitted. This is postulated to be due to the PEG treatment acting as a sealant and trapping in the acetic acid. In the case of archaeological wood, despite its age and high-molecular-weight PEG treatment, artefacts from the Mary Rose collection were found to emit acetic acid, causing lead corrosion. This highlights that, independently of its age, archaeological wood has the potential to emit acetic acid, which could be a concern when materials susceptible to acid damage are stored in the same environment. Future research should take steps towards quantifying emission rates in order to assess the potential accumulation of acetic acid in enclosures.

Author Contributions: Conceptualisation, S.H., J.G.-B., E.S. and S.G.; methodology, S.H., J.G.-B. and E.S.; formal analysis, S.H.; investigation, S.H.; resources, S.H., J.G.-B., E.S. and S.G.; writing-original draft preparation, S.H., J.G.-B. and E.S.; writing-review and editing, S.H., J.G.-B., E.S. and S.G.; supervision, J.G.-B., E.S. and S.G. All authors have read and agreed to the published version of the manuscript. 
Funding: This project has been funded by EPRSC Grant EP/L016036/1.

Conflicts of Interest: The authors declare no conflict of interest.

\section{References}

1. Gibson, L.T.; Watt, C.M. Acetic and formic acids emitted from wood samples and their effect on selected materials in museum environments. Corros. Sci. 2010, 52, 172-178. [CrossRef]

2. Tétreault, J.; Sirois, J.; Stamatopoulou, E. Studies of lead corrosion in acetic acid environments. Stud. Conserv. 1998, 43, 17-32. [CrossRef]

3. T'etreault, J. Airborne Pollutants in Museums, Galleries, and Archives: Risk Assessment, Control Strategies, and Preservation Management; Canadian Conservation Institute: Ottawa, QC, Canada, 2003.

4. Tétreault, J.; Cano, E.; van Bommel, M.; Scott, D.; Dennis, M.; Barthés-Labrousse, M.-G.; Minel, L.; Robbiola, L. Corrosion of copper and lead by formaldehyde, formic and acetic acid vapors. Stud. Conserv. 2003, 48, 237-250. [CrossRef]

5. Allen, N.S.; Edge, M.; Appleyard, J.H.; Jewitt, T.S.; Horie, C.V.; Francis, D. Degradation of historic cellulose triacetate cinematographic film: The vinegar syndrome. Polym. Degrad. Stab. 1987, 19, 379-387. [CrossRef]

6. Chakrabarty, B.; Ghoshal, A.K.; Purkait, M.K. Effect of molecular weight of PEG on membrane morphology and transport properties. J. Membr. Sci. 2008, 309, 209-221. [CrossRef]

7. Mortensen, M.N. Stabilization of Polyethylene Glycol in Archaeological Wood; Technical University of Denmark: Lyngby, Denmark, 2009.

8. Dupont, A.-L.; Tétreault, J.; Tetreault, J. Cellulose Degradation in an Acetic Acid Environment. Stud. Conserv. 2000, 45, 201. [CrossRef]

9. Curran, K.; Aslam, A.; Ganiaris, H.; Hodgkins, R.; Moon, J.; Moore, A.; Ramsay, L. Volatile Organic Compound (VOC) emissions from plastic materials used for storing and displaying heritage objects. In Proceedings of the ICOM-CC 18th Triennial Conference Preprints, Copenhagen, Denmark, 4-8 September 2017.

10. Risholm-Sundman, M.; Lundgren, M.; Vestin, E.; Herder, P. Emissions of acetic acid and other volatile organic compounds from different species of solid wood. European. J. Wood Wood Prod. 1998, 56, 125-129. [CrossRef]

11. Gu, X.; Ma, X.; Li, L.; Liu, C.; Cheng, K.; Li, Z. Pyrolysis of poplar wood sawdust by TG-FTIR and Py-GC/MS. J. Anal. Appl. Pyrolysis 2013, 102, 16-23. [CrossRef]

12. Jensen, L.K.; Larsen, A.; Mølhave, L.; Hansen, M.K.; Knudsen, B. Health Evaluation of Volatile Organic Compound (VOC) Emissions from Wood and Wood-Based Materials. Arch. Environ. Health 2001, 56, 419. [CrossRef] [PubMed]

13. Almkvist, G.; Persson, I. Fenton-induced degradation of polyethylene glycol and oak holocellulose. A model experiment in comparison to changes observed in conserved waterlogged wood. Holzforschung 2008, 62, 704-708. [CrossRef]

14. Hoffmann, P.; Singh, A.; Kim, Y.S.; Wi, S.G.; Kim, I.J.; Schmitt, U. The Bremen Cog of 1380-An electron microscopic study of its degraded wood before and after stabilization with PEG. Holzforschung 2004, 58, 211-218. [CrossRef]

15. Jalilehvand, F.; Damian, E.; Fors, Y.; Gelius, U.; Jones, M.; Salome, M. Sulfur accumulation in the timbers of King Henry VIII's warship Mary Rose: A pathway in the sulfur cycle of conservation concern. Proc. Natl. Acad. Sci. USA 2005, 102, 14165-14170.

16. Schofield, E.J.; Sarangi, R.; Mehta, A.; Jones, A.M.; Mosselmans, F.J.; Chadwick, A.V. Nanoparticle de-acidification of the mary rose. Mater. Today 2011, 14, 354-358. [CrossRef]

17. Fors, Y.; Jalilehvand, F.; Sandström, M. Analytical aspects of waterlogged wood in historical shipwrecks. Anal. Sci. Int. J. Jpn. Soc. Anal. Chem. 2011, 27, 785. [CrossRef] [PubMed] 